\title{
Derechos humanos y sistema penitenciario: poder, exclusión y contrapoder
}

\author{
Human Rights and the Penitentiary System: \\ Power, Exclusion and Counterpower
}

\author{
Yuner Ismar Flórez Eusse \\ Universidad Nacional Abierta y a Distancia (Colombia) \\ https://orcid.org/0000-0002-4251-1517 \\ pfismar@hotmail.com
}

Fecha de recepción: 30/08/2021

Fecha de aceptación: 19/10/2021

\section{Resumen}

En el presente ejercicio se realiza una reflexión sobre los derechos humanos y el sistema penitenciario, abordando categorías de análisis tales como poder, exclusión y contrapoder. Se pretende mostrar la vulneración de los derechos humanos en contextos de exclusión, donde el poder clasifica lo normal y lo que no lo es, poniendo en marcha distintos dispositivos de poder para "normalizar"; siendo en este proceso donde se limitan las libertades y se restringen los derechos, dejando de lado la dignidad humana. Se emplea una metodología hermenéutica, basada en una revisión bibliográfica que toma como principal autor a Michel Foucault, aunque puesto a dialogar con otros autores que permiten fortalecer y entender las categorías de análisis mencionadas, como es el caso del contrapoder, que es abordado desde algunos autores latinoamericanos que abogan por el empoderamiento, la identidad y la liberación, no sólo de los pueblos, sino de los sujetos oprimidos.

Palabras clave: derechos humanos, control, sistema penitenciario, poder, exclusión, contrapoder. 


\section{Abstract}

The objective of this research project is to examine issues involving human rights and the prison system. The categories of analysis addressed include power, exclusion, and counterpower as the study examines how human rights are violated in contexts of exclusion where power classifies what is normal and what is not and mobilizes distinct devices of power to "normalize" through a process in which freedoms are limited, rights restricted, and human dignity debased. The methodology is hermeneutic and interpretative, including a literature review in which Michel Foucault stands out as the main author, complemented by his dialogues with other writers that strengthen and clarify our understanding of the aforementioned categories of analysis. This is the case, for example, of counterpower, a concept that has been examined by some Latin American authors who advocate the empowerment, identity, and liberation of oppressed peoples and subjects everywhere.

Keywords: human rights, control, prison system, power, exclusion, counterpower

\section{Introducción}

Actualmente, los derechos humanos son un tema muy bien estructurado y descrito teóricamente; sin embargo, en la realidad inmediata, aún hay mucho que recorrer para que el Estado vele por su protección integral. El problema se incrementa si el cuidado de estos derechos se analiza en el campo de los excluidos sociales. Este grupo de ciudadanos "anormales" - como los llama Foucaultno son considerados apropiados para el sistema actual, ya que, al no cumplir las expectativas que el Estado ha construido sobre ellos, son marginados, aislados y reprimidos. La problemática ha llegado hasta el punto en que estos excluidos han sido deshumanizados y son tratados como el "otro" deslegitimado, incluso hasta en el momento de hacer valer sus derechos inherentes e inalienables.

Este fenómeno es invisible para la sociedad "normal", debido a que cada uno de los integrantes del sistema se ha convertido en miembro activo de lo que Foucault denominó como "panóptico"; es decir, un sistema opresor cerrado que vigila y castiga a sus internos. Se dice que los "normales" forman parte de dicho aparato porque es puesto en funcionamiento sin que el vulgo lo perciba, de manera tal que son totalmente indiferentes a la marginalidad que provoca. Esta problemática deja entre sus consecuencias el menoscabo de ciertos individuos, la 
violación de los derechos humanos y la ineficacia de la reinserción social, situación que desencadena un círculo vicioso de rebeldía, exclusión, opresión y castigo.

El objetivo del presente trabajo consiste en visualizar la transgresión de derechos humanos que se da a través de la clasificación y exclusión de las personas y los grupos más vulnerables, misma que es ejercida por quienes detentan el poder político y económico. Desde un paradigma socio-crítico e interpretativo, se realizaun análisis tanto de textos como de realidades y contextos, en este caso, de las prácticas jurídico-políticas que se arraigan en las sociedades contemporáneas, específicamente en aquellos individuos que son clasificados como anormales.

Para desarrollar el objetivo planteado, en un primer momento se propone un apartado donde someramente se clarifica y contextualiza sobre los derechos humanos, con el fin de comprender su alcance y magnitud. En un segundo momento, se presenta el sistema penitenciario como un aparato regulador y normalizador, pues la población privada de la libertad es uno de los grupos más vulnerables y discriminados que permiten comprender cómo funciona el sistema de normalización, poder y exclusión. Estos dos últimos conceptos dan pie al tercer apartado, el cual pretende mostrar cómo el poder político y económico se convierte en un instrumento normalizador y excluyente que vulnera la dignidad humana y, por lo tanto, va en contravía de los derechos humanos.

En la última sección se propone como tesis que es a través de los derechos humanos, como contrapoder, que se logra superar al Estado opresor y excluyente. Es en este sentido, que el ciudadano debe empoderarse, hacer valer sus derechos y tomar el poder a través de la democracia y la Constitución, para volverlo en contra del poder constituido, es decir, de quienes han detentado la fuerza, la opresión y el desprecio por los derechos humanos. De este modo se podrá romper con la cultura político-jurídica de normalización, minimización y deshumanización, tanto de los grupos minoritarios y vulnerables, como de los individuos mismos que pierden su identidad a causa de un sistema autómata antihumanidad que despoja al individuo de su dignidad, convirtiéndolo en un engranaje más de una maquinaria que solo quiere producción, poder y exclusión.

\section{Derechos humanos: una contextualización}

Para realizar la presente disertación en torno a los derechos humanos y el sistema penitenciario, es menester esbozar someramente el reconocimiento de estos y la trayectoria de su constitución.

En un primer momento,durante la Antigüedad, existía una postura antropocéntrica donde los derechos eran connaturales al individuo, es decir, innatos y parte de su ser ontológico. En este sentido, los derechos se entendían como 
naturales y parte de la esencia del ente antropológico. No obstante, dicha concepción distaba mucho de la realidad en cuanto a la aplicación del respeto de los derechos humanos, porque estos no se le reconocían a ciertos grupos poblacionales, como a los esclavos, las mujeres y los extranjeros o bárbaros, como se les denominaba en la Antigua Grecia.

En la Edad Media, cambió el primer fundamento que constituye la esencia de lo humano, configurándose un ente extra terreno denominado Dios. En este periodo, se creía que los derechos eran dados directamente por dicha divinidad y, al ser todos hijos de esa misma esencia,se logró cierto avance en materia de igualdad. Sin embargo, los derechos también eran limitados y podían ser violados si no se contaba con cierta dignidad, principalmente social y económica.

Hasta este punto, puede vislumbrarse que los derechos humanos eran entendidos como un ente abstracto y focalizado a ciertos grupos poblacionales, por lo que puede concluirse que una concepción más cercana a la que actualmente tenemos, nació en el mundo moderno, en el cual:

los derechos humanos [...]no son el fruto de una reflexión abstracta, sino la respuesta a situaciones concretas en las que el individuo, o el grupo humano, y su dignidad estaban amenazados o menoscabados por razones como la intolerancia, la exclusión, la concentración del poder, legitimado, además, por el derecho divino, o la indefensión ante un derecho penal y procesal arbitrarios. (Velasco, 2001, p. 117)

Teniendo en cuenta lo anterior, de cara a la modernidad, se constata que la primera Declaración de los Derechos del Hombre y del Ciudadano se da en 1789 , cuyo artículo $1^{\circ}$ dice: "los hombres nacen libres e iguales en derechos". Por su parte, en la Declaración Universal de los Derechos Humanos que se da en 1948, proclama en su artículo $1^{\circ}$ que "todos los seres humanos nacen libres e iguales en dignidad y derecho".

En consecuencia, se puede explicar la evolución de los derechos humanos según su origen, y a partir de generaciones. La primera de estas corresponde a los derechos civiles y políticos, surgida y desarrollada en las revoluciones burguesas, las cuales estaban permeadas por la filosofía liberal en la que se privilegiaba la autonomía privada. Precisamente es en este contexto que se da la Guerra de Independencia de los Estados Unidos (1777-1783), en torno a la cual se promulga la Carta de Derechos Humanos y la Constitución del estado de Virginia. Así mismo, con la Revolución francesa de 1789, emerge la Declaración Universal de los Derechos del Hombre y los Ciudadanos, mencionada anteriormente, donde se consideran los derechos civiles y políticos de los hombres.

En este primer momento, tales derechos son de naturaleza negativa, porque no hay acción del Estado al haberse limitado su poder (La Declaración de Derechos de Virginia, 1776, p. 134). En este sentido, la libertad consiste en la capacidad de hacer todo aquello que no cause perjuicio a los demás, sin que el ejercicio de los derechos naturales tenga otro límite que garantice a los demás el disfrute de los mismos. 
Posteriormente, o como parte de una segunda generación, aparecen los derechos sociales, económicos y culturales. Esta fase es socialista, ya que surge como respuesta al capitalismo y en busca de la igualdad en las clases sociales. Este momento complementa al primero, pues se habla de límites a la autonomía privada y se da una manifestación de los obreros para garantizar sus derechos y necesidades básicas; dentro de esta misma línea, es así como se considera que la Revolución Industrial fue más económica que social (González, 1998, p. 180).

Más adelante se presenta otro grupo o generación de derechos, los denominados de solidaridad. Mediante estos se busca la preservación de los seres humanos como especie, se habla ya de paz, desarrollo, medio ambiente y el patrimonio común de la humanidad, así como también de derechos colectivos. Estos derechos de solidaridad son oponibles y exigibles al Estado; la exigibilidad es positiva, mientras que la oposición es negativa.Es así como la libertad de los derechos humanos ha transitado entre libertad negativa y positiva, participación, y entre individuos, colectivos y colectividades (González, 1998, p. 180).

Con un panorama como el anterior, surge el Estado social y democrático de derecho. El concepto general de este implica la satisfacción de necesidades básicas y, por lo tanto, requiere de la intervención del Estado para lograr dicho fin - lo cual nos habla de libertad positiva- además, desde el punto de vista democrático, también implica participación, donde se considera la libertad en relación con el derecho, que de igual forma debe ser legítimo. Asimismo, reconoce la igualdad ante la ley —igualdad política - y el multiculturalismo (Villar, 2007, p. 75). El multiculturalismo se comprende del reconocimiento de un pluralismo jurídico, lo cual implica que para la interpretación de los derechos humanos se debe acudir, no sólo a ley, sino también a estándares internacionales y al derecho propio de los pueblos con diversidades étnicas y culturales: desde esta perspectiva, se habla de un Estado social y democrático plural de derecho.

Por consiguiente, se entienden los derechos humanos como un conjunto de principios que buscan un mejor nivel de vida para los individuos, sin distinción de raza, identidad sexual, religión, edad, u otros; en este sentido, contribuyen a respetar y hacer respetar la dignidad humana, que es un valor en sí mismo inherente e inalienable. Asimismo, los derechos humanos comprenden tres dimensiones: ética, política y jurídica. La ética regula la convivencia pacífica, sustentándose en la dignidad humana, la libertad y la igualdad. La dimensión política está determinada por el contexto político de la evolución de los derechos humanos, estos derechos han sido el sustento de muchas reivindicaciones sociales. Y, por último, la dimensión jurídica se refiere a la positivización de los derechos humanos, es decir, la elevación de los valores a fuerza supra legal interna.

En este orden de ideas, Bobbio (1991) sostiene que en la historia de los derechos humanos tenemos un progreso de toda la humanidad: "La Declaración Universal (...) comienza con la universalidad abstracta de los derechos naturales, pasa por la particularidad concreta de los derechos positivos nacionales, y termina con la universalidad no ya abstracta, sino concreta de los derechos positivos universales" (p. 68). No obstante, existe una interpretación diferente de los dere- 
chos humanos, donde estos son vistos como una construcción monopolizadora de la clase dominante para oprimir a las minorías, así lo permite ver Deleuze (1996) cuando refiere que "los derechos humanos no conseguirán santificar las 'delicias' del capitalismo liberal en el que participan activamente. No hay un sólo Estado democrático que no esté comprometido hasta la saciedad en esta fabricación de miseria humana" (p. 270). Así entonces, los derechos humanos como construcción de la modernidad, donde el imperativo era el desarrollo y la homogeneización de las masas, se convierten en una herramienta más para subsumir al individuo y convertirlo en un ente dominado.

Teniendo en cuenta lo anterior, a continuación se desarrollará una disertación teórica sobre la vulneración de los derechos humanos en el sistema penitenciario, desde la perspectiva de diversos autores, poniendo a dialogar a cada uno desde sus concepciones para sustentar la postura de una violación de los derechos humanos, tanto desde el sistema penitenciario, como de manera general desde el poder.

\section{Sistema normalizador y regulador}

Continuando con la lógica de esbozar las categorías más relevantes en el análisis de los derechos humanos y el sistema penitenciario desde una perspectiva foucaultiana, se pone en contexto la categoría relacionada con las prisiones y los castigos que los individuos reciben al momento que su conducta diside de los parámetros generales que rigen el comportamiento social. Esto debido a que cada ideal de justicia y de lo que es correcto o no, obedece a una cosmovisión particular, es decir, a una concepción del mundo y de la realidad ubicada en un espacio y tiempo determinado, que se generaliza o se impone como base para juzgar el comportamiento social.

Desde la Antigüedad, se ha constituido el derecho como un aparato coercitivo para reencausar las conductas que se aparten del ideario social y que se consideren peligrosas por atentar contra los demás. Sin embargo, en el deber ser del derecho, este tiene una parte pedagógica donde se socializa lo que es nocivo para la comunidad. Ya lo expresaba Foucault al decir que

Es este un gran ideal de derecho donde está inmersa la justicia, de modo que quien observe las conductas acordes con la cosmovisión de una época en un lugar determinado tenga la posibilidad de la recompensa y quien por el contrario las deje de lado sin importar su posición socioeconómica obtenga lo adverso de los que actúan observando este derecho, propendiendo no por una sed de castigo sino porque se modifiquen las conductas para el bien de la sociedad. (Foucault, 1996, p. 57) 
El ideal propuesto, en un primer momento no se considera criticable, ya que plantea como un principio y fin del derecho el bienestar general; sin embargo, al momento de realizar un análisis más riguroso, se observa una fuerza homogeneizante, y por tanto excluyente, de las minorías. La pregunta obligada es qué pasa o qué es legítimo hacer con aquellas personas que no estén de acuerdo con la comprensión ubicada espacial y temporalmente de un fenómeno determinado; este cuestionamiento permite observar el lado opresor del derecho que tolera atentar contra los derechos inalienables de una persona. En este contexto "hablamos de fuerza o de coacción cuando existe capacidad para negar o limitar a otros el acceso a determinados bienes u oportunidades: la vida, la integridad física, la libertad, el patrimonio, el trabajo" (Vallès, 2007, p. 34).

Este poder, reservado al Estado por medio del aparato penitenciario y carcelario, se ha convertido en un aparato tanto ideológico como opresor, así como en un instrumento de exclusión que permite aplicar la terribilización a quien no convenga, no al bienestar general, sino a los intereses particulares de quien detenta el poder político y económico. Desde esta perspectiva, Zaffaroni (2015) expresa que

Es bastante difícil presentar como racional el ejercicio de poder del sistema penal en la actualidad, dado su señalado carácter violento, selectivo y reproductor, pero, de cualquier modo, no es la administración penitenciaria la encargada de justificar un ejercicio de poder que no está en sus manos, sino que recibe el resultado del mismo, esto es, el producto de una selección arbitraria en la que no interviene. (p.26)

En este sentido, Zaffaroni, además de mostrar los elementos de exclusión ya mencionados, cuestiona si el sistema penal no es quien está llamado a reconsiderar dicho sistema, pues este sólo es un ejecutor de la voluntad de los poderes políticos que se han preocupado más por la manipulación de las masas que por su bienestar. Así lo corrobora Bobbio (2003) al decir que "más aún, si nos atenemos al juicio corriente, es más fácil oír que la política la hacen individuos cuyo único interés es aumentar sus propios haberes (p. 240).

El sistema penitenciario toma al individuo y lo inhibe de su propio ser, lo generaliza y lo juzga conforme al rasero general, despersonalizándolo tanto, hasta el punto en el que sus derechos fundamentales son menoscabados, pues en la clasificación de los seres humanos quienes no se ajusten al ser general son "juzgados, condenados, clasificados, obligados a cumplir tareas, destinados a cierta manera de vivir o a cierta manera de morir, en función de discursos verdaderos que llevan consigo efectos específicos de poder" (Foucault, 2000, p. 34). Esto es precisamente el fondo del sistema penal acusatorio, es un juego de poder que solo intenta normalizar a los "anormales".

Respecto a este fenómeno, Foucault proponía una sociedad disciplinaria dividida en "nosotros" y "los otros", donde los otros son forzados a ser como nosotros, por medio de los aparatos del poder del Estado. En sus palabras, 
Lo primero y fundamental de la normalización disciplinaria no es lo normal y lo anormal, sino la norma. A causa del carácter prescriptivo de la norma en relación con lo normal, el hecho de que la normalización disciplinaria vaya de la norma a la diferenciación final de lo normal y lo anormal, lo que ocurre en las técnicas disciplinarias se trata más de una formación que de una normalización. (Foucault, 2005, p.98)

Esto quiere decir que, más que una normalización de la conducta humana, es una normación de la misma; la norma pretende ser la normalizadora de la conducta, propendiendo que esta esté normada más que normalizada.

Así como el sujeto constituye una sociedad e influye sobre esta, también la sociedad crea un sujeto determinado a través de las prácticas pedagógicas de socialización y normalización. De esto puede deducirse que el individuo es producido por la acción u omisión de la sociedad. Esto, sumado a la naturaleza humana, deja mucho que pensar sobre el elemento volitivo del individuo que incurre en una conducta punitiva, Foucault lo expresaba a su manera en el momento de reconsiderar que

La relativa estabilidad de la ley ha cobijado todo un juego de sutiles y rápidos relevos. bajo el nombre de crímenes y de delitos, se siguen juzgando efectivamente objetos jurídicos definidos por el Código, pero se juzga a la vez pasiones, instintos, anomalías, achaques, inadaptaciones, efectos de medio o de herencia; se castigan las agresiones, pero a través de ellas las agresividades; las violaciones, pero a la vez, las perversiones; los asesinatos que son también pulsiones y deseos. (Foucault, 2002, p. 19)

Teniendo en cuenta lo anterior, se propone que las cárceles no se ajustan al deber ser del derecho, así como tampoco son efectivas para la modificación de la conducta de quienes incurren en ellas movidos por diferentes circunstancias o situaciones de fondo que, como se ha podido observar, no siempre están ligadas a la voluntad. Esto se sustenta a partir de que en dichos espacios se presenta una materialización de las pulsiones humanas, por lo cual resulta injusto desde todo punto de vista normalizar a quien no está de acuerdo con dichas normas, a quien los instintos humanos lo conducen por caminos diferentes. Sobre esta misma línea, Foucault propone una tesis general en la que plantea que

En nuestras sociedades, hay que situar los sistemas punitivos en cierta "economía política" del cuerpo: incluso si no apelan a castigos violentos o sangrientos, incluso cuando utilizan los métodos "suaves" que encierran o corrigen, siempre es del cuerpo del que se trata — del cuerpo y de sus fuerzas, de su utilidad y de su docilidad, de su distribución y de su sumisión-. (Foucault, 2002, p. 26)

Por tal motivo, Foucault propone que la sociedad del siglo XX es disciplinaria. De tal modo, el cuerpo es manipulado y sufre las consecuencias del sistema de castigos que se ha implementado a lo largo de la historia, ya que estos eran directamente aplicados al cuerpo físico por medio de golpes, quemaduras, etc. 
Si bien es cierto que esto ha cambiado, actualmente el cuerpo sigue siendo privado de ciertos derechos y se decide su designio según las consecuencias de las actuaciones que la sociedad considera inadmisibles.

Por otro lado, pero en la misma línea argumentativa, Foucault propone que las cárceles se convierten en lugares donde los penados son observados de manera constante. Esto ocurre en dos sentidos. Vigilancia naturalmente, pero conocimiento también de cada detenido, de su conducta, de sus disposiciones profundas, de su progresiva enmienda; las prisiones deben ser concebidas como un lugar de formación para un saber clínico sobre los penados; "el sistema penitenciario no puede ser una concepción a priori; es una inducción del estado social. (...)”. (Foucault, 2002, p. 229)

A partir de esto, la "regulación" se dilucida como un principio aplicado constantemente por el derecho, la cual consiste en absorber por completo la emancipación. Esto quiere decir que la libertad es sólo una utopía, porque al estar regulada constantemente se subordina y se hace dependiente a una comunidad cada vez más, bajo la estrategia de la disciplina que incluso la masa la reclama cuando no se le impone. La disciplina se ha traído directamente del aparato militar; el soldado, que en este caso es el pueblo, no puede pensar ni opinar, solo obedecer. Para el aparato jurídico esta estrategia para la dominación ha sido exitosa, pues según Foucault (2002) “el éxito del poder disciplinario se debe sin duda al uso de instrumentos simples: la inspección jerárquica, la sanción normalizadora y su combinación en un procedimiento que le es específico: el examen" (p. 175).

La inspección jerárquica está relacionada con la mirada pública, que se convierte en presión debido a la observación constante; sin embargo, la sanción normalizadora trata que la pena impuesta no sea observada y se minimice el impacto causado. De esta manera, el examen es el poder ideológico de revisión y valuación de la conducta, la cual se espera que esté acorde con los resultados que se proyectaron sin que la gran mayoría se percate de ello, ya "Bentham ha sentado el principio de que el poder debía ser visible e inverificable” (Foucault, 2002, p. 205).

La explicación de estos conceptos encaja perfecto en nuestra disertación, debido a que la maquinaria del poder está camuflada de modo que sólo sean tangibles los efectos; el poder se dilata conformando al derecho como un aparato de dominación donde cada individuo que pone en marcha el aparato jurídico está funcionando en pro de quien detenta este poder, y por ende la dominación; ya decía Foucault(2002) que

Hay una maquinaria que garantiza la asimetría, el desequilibrio, la diferencia. Poco importa, por consiguiente, quién ejerce el poder. Un individuo cualquiera, tomado casi al azar, puede hacer funcionar la máquina: a falta del director, su familia, los que lo rodean, sus amigos, sus visitantes, sus servidores incluso. (p. 205) 
Esto es precisamente a lo que se refiere el panóptico, “una máquina maravillosa que, a partir de los deseos más diferentes, fabrica efectos homogéneos de poder" (Foucault, 2002, p. 206). Este aparato de poder, como se ha dicho con antelación, no es propio del sistema penal, sino que es una estrategia realizada en conjunto con quienes detentan el poder, pues la "legislación introduce procedimientos de dominación característicos de un tipo particular de poder. Una justicia que se dice "igual", un aparato judicial que se pretende "autónomo", pero que padece las asimetrías de las sujeciones disciplinarias” (Foucault, 2002, p. 233).

Con lo dicho hasta el momento, no se pretende deslegitimar al derecho en su totalidad, pues el problema central radica en la dominación y las técnicas deshumanizantes y poco productivas que este utiliza para someter al individuo. En este sentido, de conformidad con Foucault, (2000)

El sistema del derecho y el campo judicial son el vehículo permanente de relaciones de dominación, de técnicas de sometimiento polimorfas. Creo que no hay que ver el derecho por el lado de una legitimidad a establecer, sino por el de los mecanismos de sometimiento que pone en acción. Por lo tanto, la cuestión es para mí eludir o evitar el problema, central para el derecho, de la soberanía y la obediencia de los individuos sometidos a ella y poner de relieve, en lugar de una y otra, el problema de la dominación y el sometimiento. (p. 36)

Desde esta perspectiva, es menester resaltar que "no hay que concebir al individuo como una especie de núcleo elemental, átomo primitivo, materia múltiple e inerte sobre la que se aplica y contra la que golpea el poder, que somete a los individuos o los quiebra" (Foucault, 2000, p.38). Por el contrario, se debe tener en cuenta que ese individuo es un ser humano, a quien asisten derechos sobre los cuales se limita el poder, incluso el poder del Estado mismo; no hay que minimizar a ese individuo convirtiéndolo en objeto puro de dominación, condenándolo y conllevándolo a la desaparición como sujeto. Sin embargo, ocurre que

Allí donde ha desaparecido el cuerpo marcado, cortado, quemado, aniquilado del supliciado, ha aparecido el cuerpo del preso, aumentado con la individualidad del "delincuente", la pequeña alma del criminal, que el aparato mismo del castigo ha fabricado como punto de aplicación del poder de castigar y como objeto de lo que todavía hoy se llama la ciencia penitenciaria. (Foucault, 2002, p. 235)

Esta ciencia penitenciaria es la que fabrica al delincuente, es decir, el mismo sistema se encarga de transformar al ser humano que ingresa en las prisiones, aniquilándolo como individuo y dejando sólo al delincuente. Es ahí donde se valida la pregunta respecto a la efectividad de la pena y el fin de la misma, pues no se está logrando crear un impacto positivo en la sociedad, ni siquiera envía mensajes constructivos, sino que, por el contrario, se convierte en un terror que amedranta a las personas porque deshumaniza a quien ingresa en las prisiones. 
Al deshumanizar a los individuos, de cierta manera se suspenden sus derechos y se convierten en invisibles para la sociedad de los "normales", ya que no hay quien se movilice y presione desde afuera por aquellos desafortunados que han sido aislados incluso de su misma condición como seres humanos.

En los centros carcelarios es tal el detrimento del sujeto que, además de deteriorar el estado físico,se afecta de manera significativa su salud mental. Ya Foucault (1982) lo expresaba al referir que

Es cierto, por ejemplo, que la constitución del sujeto loco puede en efecto ser considerada como la consecuencia de un sistema coercitivo - el sujeto pasivo-, pero usted sabe también que el sujeto loco es un sujeto no-libre y que justamente el enfermo mental se constituye como sujeto loco en relación y frente a aquel que lo declara loco. (p. 124)

Esta declaración de locura es la marca de la exclusión, ya que aquellos que no están de acuerdo con la dogmática coyuntural, que no son aceptados dentro de lo socialmente común, tienen que ser sometidos a uno de los aparatos del Estado - como la cárcel, los hospitales psiquiátricos, entre otros- para ser normalizados. Dicho sometimiento deja una marca en el individuo porque el sistema, en vez de formarlo como persona, lo deforma en delincuente, enfermo o loco.

Foucault (1989) menciona que "si el castigo pudiera ser provocado por la sola arbitrariedad de aquellos que violan la ley, ésta estaría a su disposición: podrían tocarla y hacerla aparecer a su capricho: serían dueños de su sombra y de su claridad" (p. 6); pero como esto no ocurre realmente, podemos inferir con claridad que detrás de las penas impuestas existen intereses más allá decastigar a un individuo que está en contra de un sistema. En este sentido, el castigo penal actual está viciado y motivado por situaciones externas al sujeto que comete el delito, lo que resulta injusto, situación atenta contra los derechos humanos.

Con un panorama como el anterior, es que se plantea a continuación la temática respecto al poder y la exclusión, donde se puede evidenciar cómo el poder se ha convertido en un instrumento para deshumanizar el individuo, en pro de unos intereses particulares, dejando de lado los derechos humanos y la dignidad. En este contexto, el poder es en sí mismo excluyente, porque aquellos que no estén de acuerdo con quien lo detente política y económicamente, son marginados, perseguidos e incluso exterminados.

\section{Poder y exclusión}

En lo que respecta al presente trabajo, cuando hablamos de poder, nos referimos a aquel que nace en la política, donde “generalmente el término 'política' se emplea para designar la esfera de acciones que se refieren directa o indirecta a la 
conquista y ejercicio del poder último (supremo o soberano) sobre una comunidad de individuos en un territorio" (Bobbio, 2003, p. 237). Es así como surge la pregunta obligada: ¿cuál es el fin de la acción política? La respuesta se remonta a la Antigüedad, y por tanto ha sido transmitida durante siglos hasta hoy: "la afirmación de que el fin de la política es el bien común, entendido como bien de la comunidad distinto del bien personal de los individuos que la componen" (Bobbio, 2003, p. 240). Continuando con la clarificación del poder, es relevante avizorar que "el poder político se distingue por el uso de la fuerza, se exige como el poder supremo o soberano, cuya posesión distingue en toda sociedad organizada a la clase dominante" (Bobbio, 2003, p. 243).

Dentro de la misma línea argumentativa, y trayendo a colación a Foucault, se vislumbra que el poder requiere dos elementos fundamentales que se contraponen: el primero es el conocimiento, que lo posee quien detenta el poder, cuidándolo y escondiéndolo; el segundo elemento se caracteriza por ser negativo, ya que se refiere a la ausencia de dicho conocimiento. Según el citado pensador, “el poder, cuando se ejerce en sus mecanismos finos, no puede hacerlo sin la formación, la organización y la puesta en circulación de un saber o, mejor, de aparatos de saber que no son acompañamientos o edificios ideológicos" (Foucault, 2000, p. 42). Este elemento, también lo identifica Bobbio, quien estudió juiciosamente este concepto y pone de presente que

El poder ideológico se basa en la posesión de ciertas formas de saber inaccesibles para la mayoría, de doctrinas, conocimientos, incluso sólo de información o de códigos de conducta, para ejercer una influencia en la conducta ajena e inducir el comportamiento de un grupo para actuar de una forma en lugar de otra. (Bobbio, 2003, p. 242)

El imperio, entonces, está compuesto por una serie de elementos debidamente estructurados y custodiados por quienes detentan ese poder para que no sean despojados del mismo, sino que, por el contrario, se garantice la perpetuidad de dicho poder.

Esta lógica del dominio está inmersa en el derecho, ya que dentro de ella el derecho es el instrumento por excelencia del poder, donde converge el conocimiento y la fuerza, pues, como explica Foucault (1989), "la ley, soberanamente, asedia las ciudades, las instituciones, las conductas y los gestos; se haga lo que se haga, por grande que sea el desorden y la incuria, ella ya ha desplegado sus poderes" (p. 6). La norma tiene el poder de marcar la pauta de las conductas y de convertir en anormales a aquellas que no se ajusten a los objetivos e intereses de quien detenta el poder, que decide lo que es bueno y lo que es malo, lo que conviene y lo que no a la sociedad. Al dividir las conductas en normales y anormales se legitima la exclusión, porque se divide la sociedad entre los que cumplen la norma y los que la transgreden; los que actúan conforme al derecho imperante creen tener la potestad y la capacidad de decidir sobre la suerte y sobre la conducta de quien no se ajusta al ideal de verdad de la coyuntura social y política vigente. 
Con un panorama como el anterior, donde se pone en cuestión la división social, se deja ver con claridad el principio de dividir para vencer, pues cuando las polarizaciones se acentúan, el poder dominante hace lo suyo y se oculta bajo la máscara de voluntad general; en palabras de Bobbio (2003), "en una sociedad fuertemente dividida en clases contrapuestas, es probable que el interés de la clase dominante sea asumido y sostenido incluso por medio de la cohesión como interés colectivo" (p. 242). Es por ello que la dominación que se ejerce de manera tan visible no resulta ser abominable a la masa, quien incluso la acepta de muy buena manera y la implora, pues esta dominación y ejecución del poder está disfrazada de una falsa autonomía y libertad que no es más que una obediencia mecanizada de los intereses particulares de unos dueños del poder político y de las fuerzas económicas del mercado.

Sin embargo, el poder no sólo es el conjunto de las normas o le ley como tal, sino que tiene todo un andamiaje que lo hace extremadamente complejo y, a partir de ello, se pone de presente que

La cuestión del poder se simplifica cuando se plantea únicamente en términos de legislación o de Constitución; o en términos de Estado o de aparato de Estado. El poder es sin duda más complicado, o de otro modo, más espeso y difuso que un conjunto de leyes o un aparato de Estado. (Foucault, 1980, p. 10)

En este contexto Foucaultiano, el poder es tan difuso que casi cualquier persona lo puede poner a funcionar, pero no en favor suyo, sino del sistema, cuyos beneficiados son aquellos que detentan el poder, justamente quienes crean y mantienen dicho sistema en operación.

En efecto, el sistema hace que cada individuo ejerza un seudo poder, ya que “el peligro de dominar a los otros y de ejercer sobre ellos un poder tiránico no viene precisamente más que del hecho de que uno no cuida de sí y por tanto se ha convertido en esclavo de sus deseos" (Foucault 1982, p. 119). Situación que se complica debido a que estos deseos lo pueden llevar a disidir de la conducta medianamente aceptada y, por tanto, ser propenso de ser excluido:

En una sociedad como la nuestra son bien conocidos los procedimientos de exclusión. El más evidente, y el más familiar también, es lo prohibido. Se sabe que no se tiene derecho a decirlo todo, que no se puede hablar de todo en cualquier circunstancia, que cualquiera, en fin, no puede hablar de cualquier cosa. (Foucault, 1970, p. 5)

Este principio de exclusión está relacionado de manera directa con el poder, por no decir que el poder en su naturaleza es la exclusión misma. Lo prohibido es aquello que se excluye porque no es compatible con los ideales de comportamiento que se requieren para una sociedad, según la visión coyuntural de la época y el lugar en cuestión. Por ello, quien actúe contrario a ese comportamiento general, es decir, que haga lo prohibido, se excluye, se convierte en el otro que es diferente al nosotros. 
Además, existe en nuestra sociedad otro principio de exclusión: la locura. Concepto fundamental en la teoría de Foucault, porque el pensador cimenta su base teórica en el análisis de la naturaleza del comportamiento humano, y postula precisamente la locura como un invento de la clase dominante para excluir a una población determinada, que por lo regulares el grupo que no está de acuerdo con la concepción del mundo como está generalmente aceptado.

No se trata ya de una prohibición sino de una separación y un rechazo. Pienso en la oposición razón y locura. Desde la más alejada Edad Media, el loco es aquél cuyo discurso no puede circular como el de los otros: llega a suceder que su palabra es considerada como nula y sin valor, no conteniendo ni verdad ni importancia, no pudiendo testimoniar ante la justicia, no pudiendo autentificar una partida o un contrato, no pudiendo ni siquiera, en el sacrificio de la misa, permitir la transubstanciación y hacer del pan un cuerpo; en cambio suele ocurrir también que se le confiere, opuestamente a cualquier otra, extraños poderes, como el de enunciar una verdad oculta, el de predecir el porvenir, el de ver en su plena ingenuidad lo que la sabiduría de los otros no puede percibir. (Foucault, 1970, p. 6)

Esto deja como consecuencia un conocimiento de la individualidad para poder dominarla y manipularla de manera efectiva, es así como el filósofo pretende mostrar cómo se forma el poder en el siglo XIX: “un cierto saber del hombre, de la individualidad, del individuo normal o anormal, dentro o fuera de la regla; saber éste que, en verdad, nació de las prácticas sociales de control y vigilancia" (Foucault 2001, p. 6). Teniendo como precedente lo anterior, se vislumbra que, en la medida que más se conoce al individuo, más se violenta; pues según nuestro pensador:

así como entre el instinto y el conocimiento encontramos no una continuidad sino una relación de lucha, dominación, subordinación, compensación, etcétera, de la misma manera vemos que entre el conocimiento y las cosas que éste tiene para conocer no puede haber ninguna relación de continuidad natural. Sólo puede haber una relación de violencia, dominación, poder y fuerza, una relación de violación. El conocimiento sólo puede ser una violación de las cosas a conocer y no percepción, reconocimiento, identificación de o con ellas. (Foucault 2001, p. 17)

Es apenas claro y deducible que el conocimiento es una violación del sujeto que se conoce; más si ese individuo sometido a ser estudiado, es prisionero y observado todo el tiempo. En este contexto, el control y la observación son una violación de derechos.

De esa forma, la penalidad del siglo XIX pasa a ser un control no sobre lo que el individuo hace con respecto a la ley, sino sobre aquello que puede hacer. No está de más decir que este control no está sólo a cargo de la administración de la justicia, sino por una compleja red de instituciones (psicológicas, psiquiátricas, policiales, médicas, 
pedagógicas, etc.) que conforman un poder cuya función es corregir las virtualidades (lo que pueden hacer) y no las infracciones en sí. (Foucault 2001, p. 23)

Esta situación mantiene una clara relación con el concepto de los aparatos ideológicos y represores del Estado, los cuales son una serie de brazos que funciona como un sistema integrado por varios subsistemas que tienen en común el objetivo de seleccionar a las personas y clasificarlas entre los normales y los subnormales; como lo expresa Foucault (2001),es "el medio de introducir por fin un corte en el ámbito de la vida que el poder tomó a su cargo: el corte de lo que debe vivir y lo que debe morir" (p. 230). En este caso, dar muerte no es asesinar, sino excluir, rechazaral otro; decidir quién está en perfectas condiciones para hacer parte del sistema homogeneizante y quién es susceptible de ser apartado de la sociedad de los normales.

El análisis realizando hasta el momento no es meramente enunciativo, es una herramienta que permite entrever las posibilidades de acción con las cuales los excluidos, los locos y aquellos a los que se les violan sus derechos de manera arbitraria porque no comparten la normalidad con los que siguen los ideales socialmente aceptados, cuentan para ganar terreno en la lucha por el respeto y reconocimiento de su individualidad. En concordancia con lo dicho por Foucault,

El análisis de los mecanismos de poder no tiene como finalidad mostrar que el poder es anónimo y a la vez victorioso siempre. Se trata, por el contrario, de señalar las posiciones y los modos de acción de cada uno, las posibilidades de resistencia y de contra-ataque de unos y otros. (Foucault, 1980, p. 13)

La investigación teórica y la contextualización categórica de la realidad sólo tiene sentido en el momento que se pretenda una actuación concreta en el campo fenoménico y que no se quede sólo el mundo teorético. Por ello, damos continuación al análisis abordando la categoría de derechos humanos y contrapoder, que compone la parte propositiva del presente trabajo, donde los derechos humanos deben ser apropiados por el pueblo contra ese poder constituido para excluir y exterminar la dignidad humana.

\section{Derechos humanos y contrapoder}

Como mencionábamos con anterioridad, los derechos humanos son utilizados para efectuar dinámicas de poder y dominación que velen por los intereses particulares de las institucionesque tendrían que garantizar, precisamente, dichos derechos. Sin embargo, el poder no es estático ni definitivo, el "poder tiene que ser analizado como algo que circula, o más bien, como algo que no funciona sino 
en cadena. No está nunca localizado aquí o allí, no está nunca en las manos de algunos" (Foucault, 1992, p. 152). Esto último permite y da la posibilidad de actuar a aquella parte de la sociedad que no detenta el poder. Así entonces, el poder en sí mismo no es negativo, en realidad es la fuerza que permite la lucha; sin embargo, para que la lucha sea afectiva tiene que darse en el plano de la participación y organización social y política de las clases menos favorecidas, de los locos, de los excluidos, de aquellos anormales, que deben empoderarse y convertir el poder en contrapoder.

Desde esta perspectiva, el contrapoder es la acción del que no detenta el poder, resistiendo. Esto lo expresa Foucault (2010) cuando pone de presente que

Políticamente hablando (...) resistir significaba simplemente que no. Se había conceptualizado la resistencia sólo en términos de negación. Sin embargo, tal como ahora lo comprende usted, la resistencia no es un acto únicamente de negación: es un proceso de creación; crear y recrear, transformar la situación, participar activamente en el proceso, eso es resistir. (p. 1052)

Es por ello que la actitud más peligrosa en este contexto es la indiferencia, pues existe una clase que detenta el poder y trabaja de manera constante el perfeccionamiento de sus técnicas de opresión y reproducción de dicho poder, pero una gran mayoría ni se entera de lo que sucede — ya sea porque no les interesa participar, o porque no ven los resultados inmediatos, o porque los resultados no están orientados a ganancias particulares-, actitud que sólo favorece a quien domina el poder político y económico. Es por ello que se dirige a las minorías un llamado a resistir, creando medios de participación, de hacer del contexto próximo un conjunto de posibilidades para ganar territorio en el reconocimiento de los derechos de las personas sin distingo alguno.

Sobre esta misma línea, se habla de minorías no en el sentido peyorativo, sino entendiéndolas como aquellos que conciben la realidad de manera distinta. Ya lo decía Chávez y Magoja (2011):

Las minorías no son otra cosa que líneas de fuga que escapan a ese poder normalizador y regulatorio de la vida. Fugas minoritarias que no pueden ser controladas, tampoco suprimidas ni calladas y que ponen en tela de juicio el modelo dominante. Creemos que las minorías mencionadas son fuerzas creativas: creadoras de vida, de vivencias colectivas que fisuran y rompen las estrategias y prácticas del biopoder. Como ya dijimos, las minorías son pequeños movimientos que ejercen la vida como contrapoder y que, podríamos concluir, practican los Derechos Humanos en tanto defienden desde su propio lugar aquello que les pertenece. (p. 28)

Así entonces, de acuerdo con Dussel, (2001) "la crítica ético-política tiene pretensión de establecer la no-verdad, la no-validez (deslegitimación), la no-eficacia de la decisión, norma, ley, acción, institución u orden político vigente e injusto 
desde la perspectiva específica de la víctima" (p. 58). Se pretende entonces, que se tomen cartas en el asunto donde en un primer momento, como se ha mencionado en repetidas ocasiones, se realice el develamiento de los principios que constituyen las dinámicas legales actuales para que, de este modo, se deslegitime la praxis socio jurídica que no esté acorde con las necesidades de las víctimas, es decir, de la clase que siempre ha estado excluida y oprimida y que nunca es tenida en cuenta realmente para las decisiones del Estado. Esto requiere una participación activa y una concepción crítica de la realidad, de modo que se desligue de inmediatismos políticos e intereses egoístas y se constituya el logos en un diálogo intersubjetivo, el cual debe estar precedido por una reflexión de un pensar serio y autónomo, pues

No hay diálogo verdadero si no existe en sus sujetos un pensar verdadero, pensar crítico que, no aceptando la dicotomía mundo hombres, reconoce entre ellos una inquebrantable solidaridad. Este es un pensar que percibe la realidad como un proceso, que la capta en constante devenir y no como algo estático. (Freire, 2005, p. 75)

Para cumplir con este objetivo, se deben tener en cuenta las características propias de una comunidad y respetar las diferencias, propendiendo siempre que el marginado, el oprimido, hable con voz propia, porque nadie conoce mejor sus necesidades que él mismo. Esto aplica también para países enteros en los que se han adoptado sistemas legales de otros contextos que nada tiene de similar en cuanto a cultura y costumbres, teniendo en cuenta que la costumbre se considera como una fuente del derecho, y si el derecho que se tiene en determinado lugar no está acorde con las costumbres de esa comunidad, por ende, no va estar ajustado a las necesidades contextuales. Por ello,

Desde el contexto histórico de América Latina creemos que el primer presupuesto es el de crear las condiciones para que los pueblos hablen con voz propia, es decir, para que digan su propia palabra y articulen sus logos sin presiones ni deformaciones impuestas. (Fornet-Betancourt, 2009, p. 8)

Cada comunidad comprende su propio logos, es por ello que, sin caer en subjetivismos absolutos, cada individuo que la conforma debe ser tomado en cuenta, porque al mismo tiempo las posibilidades de ese individuo están en cierto modo supeditadas por la comunidad micro y macro a la que pertenece, y el individuo en suma compone las dinámicas de la comunidad que la conllevan al desarrollo o al fracaso. Es en esta cuestión que radica la importancia de que el derecho comprenda el logos concreto del contexto al que se está aplicando, para que el individuo se identifique con el derecho que le es brindado y se apropie del mismo, expandiéndolo a los demás, evitando así que se torne el derecho como una imposición de una ideología determinada, que además es ajena y pugna con las características socioculturales de los individuos que la componen. De este 
modo "la idea es facilitar que cada persona tenga los recursos y la oportunidad para cultivar virtudes y relaciones valiosas, y disfrute las buenas cosas en vida" (Chan, 2001, p. 28).

Porque el derecho surge precisamente de los conflictos entre partes, es menester las buenas relaciones conformadas desde unos principios meramente humanos, para que, en este sentido, el aparato jurídico no esté a favor de una sola clase con mayor poder o capital, sino por quien invoque la protección de su derecho y se haga una justicia real.

\section{Conclusiones}

En un primer momento, se vislumbra que el poder, así sea tiránico, se va normalizando en quien es ejercido, pues el mismo sistema transgrede ideológicamente al individuo y lo hace sentir culpable y merecedor de sucesos abruptos que no deberían ocurrir si primara la dignidad humana y el ideal de resocialización en el sistema penitenciario. Con ello se corrobora lo que se ha planteado en la discusión, donde el poder ideológico se asienta en grupos vulnerables y, aprovechando tal circunstancia, realiza un cambio sustancial y formal del pensamiento individual del sujeto, convirtiéndolo en un eslabón que se pierde en la multitud y que deja de existir por sí mismo para convertirse en un tenue reflejo del ideal requerido en una coyuntura creada en una época determinada.

Por otro lado, pero en la misma línea de argumentación, es innegable la exclusión a la que son sometidos los que no se ajustan al canon normativo impuesto por quien detenta el poder. Aunque los juicios se jactan de ser subjetivos y realizar análisis particulares en cada caso, el rasero para medir las penas se queda corto en realizar análisis de las circunstancias y aspectos socioeconómicos que rodean un hecho punible. Estas personas privadas de su libertad, además de ser normalizadas en sus celdas, también son adoctrinadas para aceptar, y en algunos casos aplaudir, los atropellos que cometen los mismos compañeros, negándoles con esto el derecho de la libre expresión.

También se puede vislumbrar un aparato de poder bastante fuerte que deja ver su brazo ideológico, donde se aísla del saber al excluido; y, por otro lado, un brazo represor perteneciente a ese poder, el cual condiciona la dignidad y los derechos humanos, situación desoladora para el sistema penitenciario, pues estos deben ser incondicionados e inherentes, pero como tales hechos ocurren dentro de lugares invisibles para la sociedad de los "normales" no son relevantes y no existe la solidaridad por parte de quienes creen ser libres, porque aún no han estado en una situación donde el sistema los excluye. El excluido es cosificado y despojado de su condición de igual por ser diferente y debe ser tratado como tal sin miramiento alguno. Al excluido se le crea por medio del aparato 
ideológico la sensación que lo que se hace con él es justo y retributivo y que él mismo es el culpable de todo el maltrato físico y psicológico al que son sometidos los anormales excluidos del sistema.

Con un horizonte como el anterior, donde se alcanza a vislumbrar una serie de elementos que permiten realizar elucubraciones de corte deductivo, donde existe un poder silencioso y silenciador que minimiza el impacto psicosocial de la violencia y agresividad que existe dentro del sistema penitenciario, es menester realizar un llamado a la resistencia, donde exista un empoderamiento a modo de contrapoder. De este modo podrá constituirse una realidad plural, donde los excluidos tengan voz y voto. Lo anterior debe ser algo colectivo, no solamente de los que no son tenidos en cuenta, sino de la sociedad en general, debido a que son políticas de expansión del poder y vulneración de derechos humanos que incumben a todos y ponen en peligro la dignidad humana.

\section{Referencias}

Bobbio, N. (2003). Teoría general de la política. Madrid: Editorial Trotta. Bobbio, N. (1991). El tiempo de los derechos. Madrid: Editorial Sistema. Chan, J. (2001). Producción del sentido de justicia confuciana. Recuperado de http://them.polylog.org/3/fcj-es.htm

Chávez, C. y Magoja, E. (2011). Los derechos humanos como contrapoder inmanente de las minorías. Una lectura a partir de la obra de Michel Foucault. Buenos Aires: Universidad de Buenos Aires.

Deleuze, G. (1996). Conversaciones. Valencia: Pretextos.

Dussel, E. (2001). Hacia una filosofía política crítica. Bilbao: Descleé De Brower. Recuperado de http://enriquedussel.com/txt/53.Hacia_filosofia.pdf

Fornet-Betancourt, R. (2009). Filosofía intercultural. En E. Dussel, E. Mendieta y C. Bohórquez (eds.), El pensamiento filosófico latinoamericano, del Caribe y “latino” (1300-2000). Historia, corrientes, temas, filósofos. México: CREAF/Siglo XXI. Recuperado de http://www.ceapedi.com.ar/imagenes/ biblioteca/libreria/412.pdf

Foucault, M. (1970). El orden del discurso. Buenos Aires: Tusquets Editores.

Foucault, M. (1980). El ojo del poder, entrevista con Michel Foucault. En J. Bentham, El panóptico, Barcelona: La Piqueta.

Foucault, M. (1982). Hermenéutica del sujeto. Madrid: Ediciones de la piqueta. Foucault, M. (1989). El pensamiento del afuera. Valencia: Pretextos.

Foucault, M. (1992). Microfísica del poder. Madrid: La Piqueta.

Foucault, M. (1996). La verdad y las formas jurídicas. Barcelona: Editorial Gedisa. Foucault, M. (2000). Defender la sociedad. Argentina: Fondo de Cultura Económica.

Foucault, M. (2001). La verdad y las formas jurídicas. Gedisa 
Foucault, M. (2002).Vigilar y Castigar. Nacimiento de la prisión. Argentina: Siglo XXI.

Foucault, M. (2005). Seguridad, Territorio, Población. Argentina: Fondo de Cultura Económica.

Foucault, M. (2010). Estética, ética y hermenéutica. Barcelona: Paidós.

Freire, P. (2005). Pedagogía del oprimido. México: Siglo XXI

González, N. (1998). Los derechos humanos en la historia. Bellaterra: Universidad Autónoma de Barcelona.

Vallès, J. (2007). Ciencia Política una introducción. Barcelona: Ariel.

Velasco, D. (2001). Pensamiento político contemporáneo. Bilbao: Universidad de Deusto.

Villar, L. (2007) Estado de derecho y Estado social de derecho. Revista Derecho del Estado, 20.

Zaffaroni, E. (2015). La filosofía del sistema penitenciario en el mundo contemporáneo. En G. Bardazano, et al (Comps.). Discutir la cárcel, pensar la sociedad. Montevideo: Universidad de la República - Ediciones Trilce. 